\title{
Performance Measurement in Internet Gaming Industry - Implementing An Effective Balanced Scorecard at An Online Casino
}

\author{
Swen Günther \\ Katja Meyer \\ HTW Dresden, University of Applied Sciences \\ Friedrich-List-Platz 1, 01069 Dresden, Germany \\ E-mail: swen.guenther@htw-dresden.de
}

\begin{abstract}
Performance Measurement Systems (PMS) are widely known and used in business practice. In business administration, esp. Controlling, PMS is a steady component in research and education. Over time, a lot of different versions have been developed in order to take the specific requirements of companies and sectors into account. They range from conventional PMS to highly complex, hierarchy-related Controlling Systems. The common goal of all these versions is to improve the planning and management of organizations and processes. According to the literature, the PMS is a standard management tool in many industries all over the world and could be transferred to almost any kind of product or service. In this article, we will investigate how PMS can help to improve the competitiveness of online casinos. So far, there are no articles or case studies published on this specific field of interest. The topic itself is very new and innovative even though the first online casinos have existed for more than ten years. Based on the case study of an online casino, we will show how an effective PMS could be implemented by using the classical Balanced Scorecard (BSC) in order to resolve management planning issues. The authors will demonstrate how this concept can be a "blueprint" for other e-business sectors while also considering the specific challenges, e.g. rapid (technological) development and fierce competition.
\end{abstract}

Keywords: performance measurement, balanced scorecard, e-business, online casinos, Internet Gaming

DOI: $10.7176 / \mathrm{EJBM} / 11-18-13$

Publication date:June $30^{\text {th }} 2019$

\section{Introduction}

1.1 Evolution of Internet Gaming industry and online casinos

At once, the World Wide Web dramatically changed business operations and offered entirely new business concepts for consumers in many industries. Initiated by the Free Trade \& Processing Act of Antigua and Barbuda in 1994, the first online casinos introduced real money gambling to the internet. From its humble beginnings, marked by the companies Microgaming and Cryptologic, who introduced early technologies to process money transactions and launch game engines, the sector has developed rapidly (Manuela \& Larson, 2013).

The first online casino, Intercasino, and many of its early competitors are still operating and were joined by a broad variety of Internet Gaming websites (Straub, 2019). Sparked by constantly improving software and additional features, the industry quickly became highly competitive. Shortly after casinos the first online sportsbooks joined the Internet Gaming sector (Gamblingsites.com, 2016). Today they dominate the market, leaving only a $12 \%$ share of market revenue to online casinos in Europe (European Gaming \& Betting Association, 2016). The introductions of online poker, progressive jackpots, multiplayer functions, live casino games, and mobile technologies further accelerated the growth of this industry.

In only two decades the Internet Gaming sector has developed into a successful industry generating $€ 39.4$ billion of online Gross Gaming Revenue (GGR) globally in 2016. The European Gaming \& Betting Association (2016) forecasts an expected growth of up to 50\% in GGR until the year 2020. According to Quotenmeter (2016), 7 Mio. people in the EU partake in online gambling activities on a regular basis. The dynamic European Internet Gaming sector, in addition to offline casinos, has been made possible by the introduction of regulations in states like Malta, the Isle of Man, or Gibraltar. Despite prior success, ongoing regulatory changes continue to be a major influence on Internet Gaming companies.

Regarding the legal situation, the regulations in Europe still vary from country to country and have not been standardized yet. According to EU regulations online gambling is legal (Quotenmeter, 2016). Several members of the EU have embraced it, e.g. UK and Italy, while several others have partly or entirely banned online gambling. Yet, there remain a few countries like Germany which find themselves in a legal gray zone; it is neither legal nor illegal. Therefore, the EU commission is putting pressure on these EU members to legalize the online gambling sector.

In an environment characterized by continuous development and fierce competition, a focused approach to goal setting, management, and revision can contribute to successful business performance. The performance 
measurement (PM) concept combines these areas and offers a variety of systems for its implementation. The main principle of PM is to supplement the financial measures with non-financial indicators. In combination with strategy translation and a feedback mechanism, PMS provides the basis of performance management (Balanced Scorecard Institute, 2016).

\subsection{Tailored PMS for online casinos as a challenge}

The purpose of this paper is to create a tailored PMS for an online casino focusing on the German market based in Malta. Thereby, it aims to adapt the established PM concept to the specific industry of online casinos. This requires combining the design of an adjusted PMS on the basis of literature and the application within the introduced case study work. To achieve this aim, the paper identifies requirements composing effective BSC concepts based on the current level of research within specific industries.

To fulfil requirements and promote new practices, the studied online casino requires a common structure to define objectives, measure progress, and review achievements. However, the dynamic market environment and the small size of the company appear to characterize a business unfit for traditional management approaches as a classic performance measurement, e.g. the BSC. Since the Industrial Revolution PM has grown in popularity, and the BSC has emerged as a broadly utilized management approach (Bititci, 2015). By providing tools for understanding, managing, and improving organizational activities, a PMS supports the precise representation of performance versus objectives. Moreover, it facilitates the measurement of customer satisfaction and internal obstacles, which fosters a future-oriented business approach and supports business competitiveness and considerable growth (Franceschini et al., 2007).

These characteristics highlight the potential value of PMS for the studied online casino. However, traditional PMSs appear to lack applicability to modern industries and, therefore, require adaption (Bititci, 2015). Based on literature the following three findings support the relevance of this paper and will be taken as a guideline for the research work:

- Little research has been conducted on the online casino business and performance management (Repetti, 2011; Williams \& Wood, 2007).

- The BSC can serve as a basis for the development of PMS for specific industries (Richard et al., 2009; Jaeaeskelaeinen \& Laihonen, 2014).

- The use of the BSC for specific industries requires alterations of the BSC concept (Bremser \& Chung, 2005; Kaisheng \& Xiaohui, 2011).

\section{Literature Review}

\subsection{Balanced Scorecard (BSC) as wide-spread PMS}

Today PM forms an integral part of the performance management process of organizations (Franceschini et al., 2007). The management of performance can be defined as the process an organization deploys in order to manage its performance in alignment with vision, strategy, and objectives by the use of various information systems. It is obvious that PM has outgrown the basic process of collecting, analyzing, and reporting of business activity information. The data driven measurement focus shifted towards integrated systems and active management.

Therefore, a PMS can be described as an enabler of strategy deployment at all business levels, which collects relevant information in order to provide proactive feedback and support the management decision making process. In this context it utilizes a variety of indicators, which reflect financial and non-financial aspects of internal and external circumstances to provide feedback. The selection of indicators alone serves as a valuable tool for strategy deployment (Schreyer, 2007). As a response to the growing complexity of measuring organizational performance, various measurement frameworks have been published since 1980's. Despite the broad variety and continuous development of new frameworks, only few models successfully managed to transition from theory into practice.

As one of the widest spread performance measurement frameworks, the Balanced Scorecard is well-known, utilized and discussed (Gleich, 2011). Developed in 1992 by Kaplan \& Norton, the model has, since it was initially published, been developed from a simple performance framework into a complete strategic management tool. This is accomplished by the translation of company visions and strategies into measures determining progress and success (Distelzweig, 2014). In their work Kaplan \& Norton recognized the limitations of traditional, financially focused measures which reflect upon historical decisions, but lack the ability to guide and evaluate the creation of future value. Therefore, emphasis was put on the need to provide executives and managers with a balanced view of an organization's performance, in which financial results are supplemented with future predicting measures (Balanced Scorecard Institute, 2016). The low complexity and flexibility towards strategic orientation (Greiner, 2012) as well as the individual tailoring (Richard et al., 2009), and highlighting of cause-effect-relationships (Reichmann, 2011) are cited as major advantages of the BSC. However, despite its wide-spread usage, the BSC has many critics.

The origins of PM can be found in the Second Industrial Revolution and are strongly influenced by massmanufacturing. Hence, most frameworks focus on large manufacturing companies and disregard other industries. 
The lack of applicability has spurred the research of PM in a variety of industries in recent years (Bititci, 2015). This study begins by reviewing relevant literature for the Internet Gaming industry. However, business-focused literature about online casinos is rare.

In his paper, Repetti (2011) concludes that, despite the growth of studies concerning the casino industry, the sector is still underrepresented compared with other industries. He recognized an absence of consumer behaviour, revenue influences, and operational changes for casino businesses as research topics. Within this industry, specifically, he identifies a lack of empirical studies. Similar findings are represented in Williams \& Wood (2007) with the addition of consumer characteristics and game preferences as under-researched issues. Following these findings the literature lacks studies combining the performance measurement concept with online casino businesses.

\subsection{Augmentation of the BSC for online casinos}

Consequently, this chapter reviews publications describing the usage, characteristics, and designs of PMS in specific industries sharing characteristics with online casinos. E-commerce, e.g. online stores, is a business that shares characteristics with online casinos. Similarities mainly arise from the environment and operational processes of web-based businesses. However, due to these characteristics (see Figure 1), e-commerce is a business form rather unfit for the implementation of classic PMSs. The resulting need for more context adapted approaches in the e-business industry was pointed out by Barnes \& Hinton (2012).

\section{Characteristics of Online Casinos}

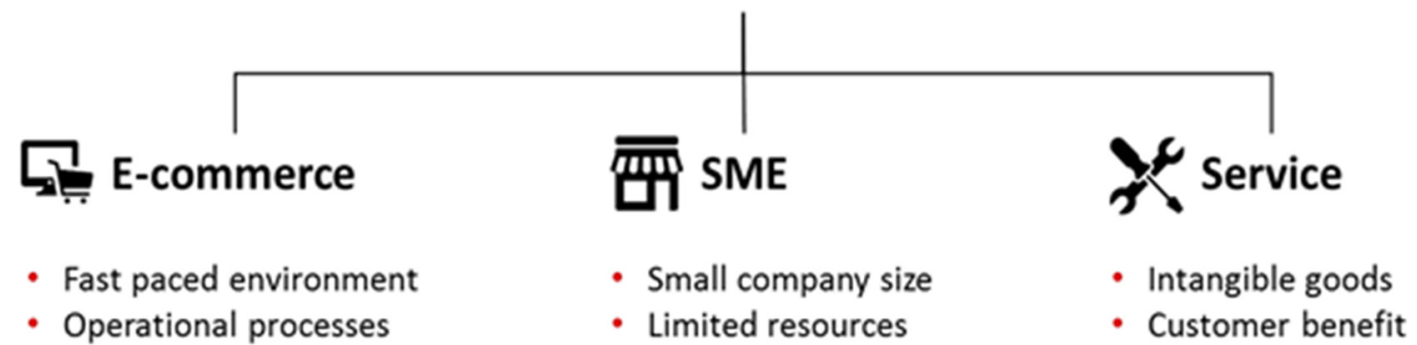

Figure 1. Specific industries sharing characteristics with online casinos

Kaisheng \& Xiaohui (2011) address the uncertainty of the e-business environment in their study and describe it as a result of the combination of dynamic customer behaviour, constantly increasing market competition, and unpredictable actions of various stakeholders. They applied the BSC model to the e-business environment and found the focus on traditional and financial measures unsuitable. Subsequently, they make two recommendations for e-business performance measurement under the BSC concept:

- Focus on non-financial, forward-looking measures

- Be selective in the use of traditional measures.

Likewise, Bremser \& Chung (2005) researched the BSC for e-businesses. The main challenges highlighted in their study are rapidly changing environments and differentiated key measures arising from organizational designs of e-business models. Additionally, constant change in strategy, as a reaction to environmental pace and, consequently, changing measures are brought into focus. Their study suggests the augmentation of the BSC with two additional perspectives:

- Expansion to account for e-business (clicks)

- Expansion do account for external constituencies.

Further performance measurement research focuses on the application of PMS in small and medium sized enterprises (SME). In general, a SME is classified as a company fulfilling the following: "(1) 50 to 250 employees, (2) annual turnover of $€ 7$ to 40 million, (3) total assets less than $€ 27$ million, and (4) not more than 25 percent ownership by a large corporation" (see Business Dictionary, 2016). Most of today's online casino businesses match these criteria and, therefore, the existing literature on SME's should be considered as well. Depending on company size, the following characteristics especially have been explored within online casino businesses as SME (Garengo et al., 2005; Hudson \& Bourne, 2001):

- Resources: The number of available employees directly influences the time needed to implement PMS. Additionally, SMEs often depend on a limited number of customers and markets to invest in PM software due to limited financial resources.

- Formalization: Little authority, flat and flexible organizations as well as informal processes can lead to a lack of managerial capacities and present barriers to the introduction of PMS. Additionally, SMEs are characterized as informal organizations and, therefore, often lack strategic alignment. 
- Misconception: SMEs are characterized by a fire-fighting mentality, inducing a reactive approach to management. PM, therefore, is conceived as a bureaucratic system hampering flexibility.

Another industry in need of more adjusted PMSs is the service environment. In the service industry no tangible goods are normally produced, but work is performed for the benefit of a customer (Business Dictionary, 2016). Online casinos do not provide tangible goods, but offer a service for the entertainment of the customer. Therefore, the customer's presence can be identified as a prominent and influential characteristic of operations within both sectors.

Amir (2014) expresses in his study the uniqueness of service operations in regard to PMSs. He names the service quality, resource utilization, service flexibility and innovation as main focus areas of service businesses and concludes that company size and the nature of service influence performance measurement processes. Specifically, smaller companies are identified as valuing informal, flexible approaches which enhance communication. The study of Jaeaeskelaeinen \& Laihonen (2014) focuses on distinctive features of service performance measurement and presents a split view on combining PM and service businesses by different approaches, e.g. by focusing on common success factors and on common operations. Thus, the paper concludes to have found no limitations for the applicability of common PMSs in the service industry. However, three areas in need for company specific adoption are highlighted:

- Distinctive measures for service characteristics and service organization type

- Separation of service supply chain and service network effects

- Measurement of customer view, e.g. increase customer satisfaction.

\section{Conceptual Framework}

\subsection{Design of PM framework}

Based on the studied sources the aim of this chapter is to develop a generic PMS for online casinos. Due to the variety of PM models, a common set of guidelines is not yet established for the development process of PMS. However, two development areas can be separated (Schreyer, 2007). The first area of development concerns the basic design of the PMS as an entire concept. The second area describes the structured development of Key Performance Indicators (KPI) that usually represent the core of performance measurement.

Different processes can be found in the associated literature of various PM frameworks (i.e. Kaplan \& Norton, 1992; Eccles \& Pyburn, 1992). In this study, we would like to follow the approach of Franceschini et al. (2007), who drafted a construction process independent of a specific measurement framework. The three basic aspects, including tools to facilitate development, are as follows:

- Analyze the strategic goals of the company to link the PMS

- Draft all key processes to understand the business process

- Identify the relevant stakeholders and understand their needs

As the reviewed literature for the application of PMSs in specific industries did not point out any principal obstacles in the use of the basic BSC concept as a starting point for adaption, the proposed framework fundamentally takes on the idea to create a view of a company's strategy from different performance perspectives (see Figure 2). Hence, the principal aim of this framework is the balanced measurement of strategic objectives. Objectives are derived from a breakdown of the overall strategy focused on key processes. A balanced measurement is created by perspectives reflecting stakeholder interests, e.g. top management, employees, customers, suppliers and external authorities.

Performance Perspectives can be numerous, and prioritization varies between industries and companies. Ideally, perspectives serve as a balancing instrument for measurement (Töpfer, 2000a). The optimal balance is determined by the recipients of the measured information and differs depending on interests. Therefore, the developed model proposes an analysis of stakeholders and their motivations to indicate the main performance perspectives a company will face. Above all, it is crucial to include internal and external stakeholders in the analysis.

Therefore, Garengo et al. (2005) recommended focusing on few main stakeholders. The four perspectives "Financial", "Customer", "Internal Processes", and "Organizational Capabilities", as utilized in the standard BSC approach, are chosen as the ideal grouping of main stakeholders. However, many authors like Bremser \& Chung (2005) stress the necessity of augmenting the BSC perspectives. Accordingly, an additional "External Environment" perspective is added in order to acknowledge the dynamic of the online casino environment. It concentrates aspects of competition, legislation, and technical developments. Furthermore, it considers the interests or requirements of the following stakeholders: primary suppliers, regulatory authorities, and industry associations. 


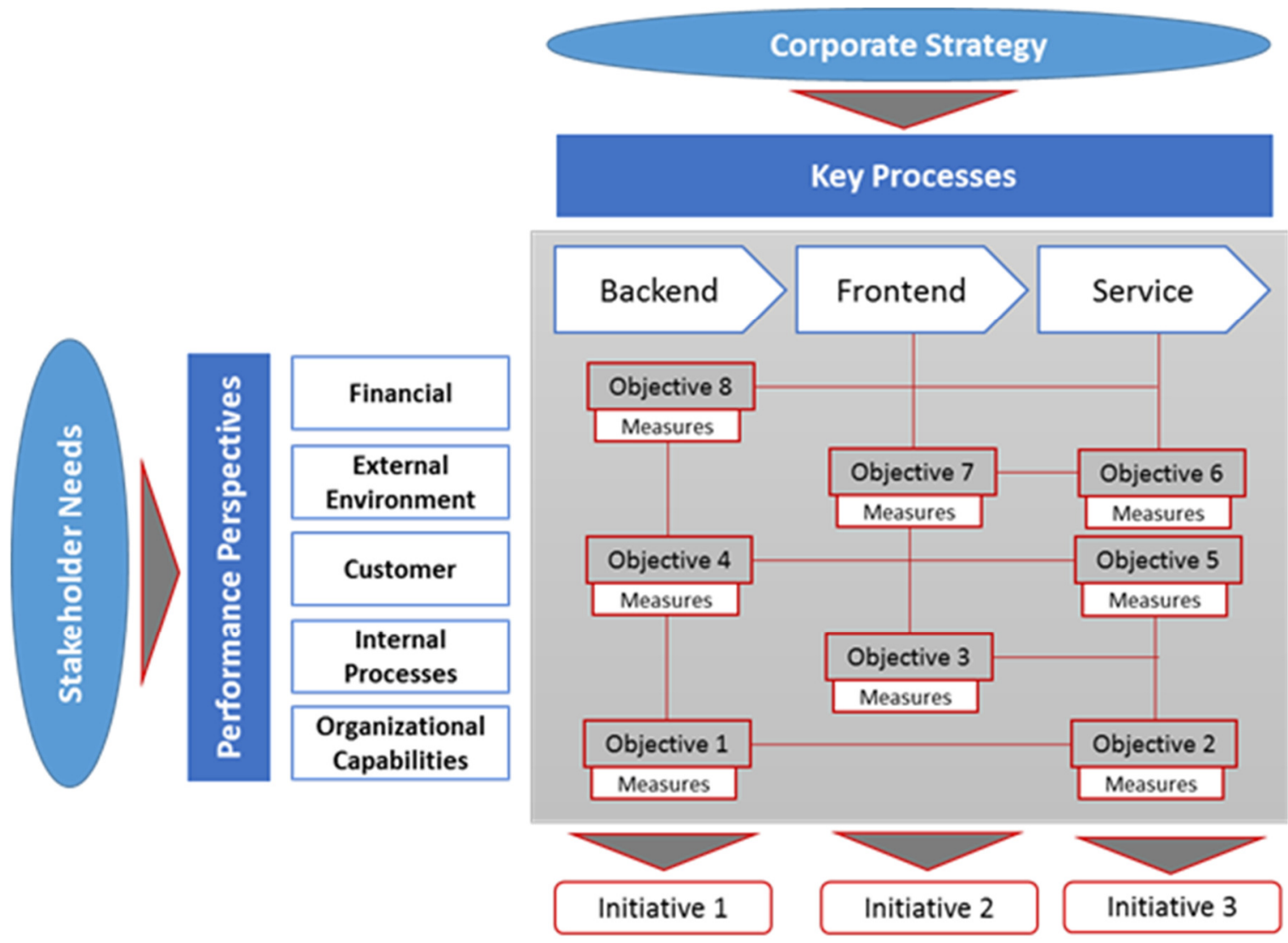

Figure 2. Generic performance measurement framework for online casinos

Key Processes are commonly understood as tasks that are crucial to the firms purpose of creating value for its shareholders. The proposed model further defines key processes as being critical to business execution, customer satisfaction, market position, competitive advantage, or strategy fulfilment (Meier \& Stormer, 2008). Hence, management of efficiency and effectiveness of these processes in alignment with strategy is significant. To determine the key processes in the proposed PM framework, high priority should be given to target customers and responsible departments.

An exemplary value chain of an online casino business consists of the three processes "Backend", "Frontend", and "Service". Thereby, the key process "Backend" covers all aspects invisible to the customer, like supplier relations, technology infrastructure and game management. "Frontend" encompasses provision and presentation aspects, like website design, marketing, acquisition, and retention activities. The third key process group "Service" concerns customer interaction during and after the use of the online casino. After defining the key processes, the requirement is, in standard practice, to define and control one or more objective per process.

Objectives or strategic objectives represent parts of the initiated strategy relevant to individual key processes in relation to certain performance perspectives. According to the initial BSC concept of Kaplan \& Norton (1992), they form the basis to develop measures, targets, and initiatives. To accomplish a chosen strategy, a breakdown of objectives and actionable tasks is crucial. Objectives are individually supplemented by a set of measures in order to track progress and identify completion. Accordingly, each measure will be held against a target value. Initiatives, i.e. action plans, represent the final level of the developed PMS and facilitate the achievement of strategic objectives.

\subsection{Development of KPIS}

KPIs are a largely discussed topic and are commonly defined as figures which represent circumstances in a concentrated, quantitative manner. The main characteristics summarized in this definition are the representation of circumstances as a display of information and the concentrated, quantitative manner, which provides clear and relevant information (Reichmann, 2011). The basic concept of all integrated PM frameworks is based on the understanding that, in isolation, an indicator does not provide a sufficient view of performance. Hence, at the core of these frameworks is the organization of KPIs into the system of identified perspectives and objectives.

In practice this includes the identification of Success Factors representing strategic objectives and stakeholder interests, e.g. market share as a success factor for increased competitiveness. Furthermore, it develops an appropriate set of indicators to value the efficiency and effectiveness of business activities accordingly. The 
collected information can thus be used to represent improvements, performance and strategy alignment. Other purposes lie in the visualization of cause-and-effect relationships and, consequently, the enhancement of crossfunctional communication (Schreyer, 2007).

The composition of this system is crucial for its ability to perform desired tasks (Reichmann, 2011). To manage the balanced composition of a measurement system, different classifications of KPIs can be used. Thus, the system can be connected to (Franceschini et al., 2007):

- Location of indicators within the value chain

- Level of (vertically) integration of KPIs

- Predictive capacity of single indicators.

The last classification differentiates between lagging and leading indicators. Lagging indicators are described as measuring historical data after an action was performed. Leading indicators, on the other hand, are future oriented and predictable in nature. Comparatively, lagging indicators describe outcomes, while leading indicators focus on success factors. The identification of leading indicators and their management play an important role in online casinos as a fast-growing market.

$\mathrm{PM}$, as a tool for strategy implementation and control, highlights the importance of a relevant connection between objectives and indicators. Hence, the development of KPIs begins after the creation of objectives, which translate strategy into individual business units. In PM literature, several approaches to derive KPIs are discussed, e.g. spreadsheet or relationship matrix to analyze the connection of targets, objectives and indicators (Töpfer, 2000b). Additionally, a performance measure record sheet is used in order to combine all relevant data concerning a single KPI.

\section{Case Study}

\subsection{Company profile \& Starting situation}

In this chapter the generic PM framework is applied to an online casino company. After introducing the company profile and drafting the initial situation, we will explain the company's specific design of PMS and, based on this, the development of KPIs. Within the competitive European market and under Maltese regulation, the examined brand for sports betting in Germany has established itself as a market leader. This same company's online casino is striving to parallel this success. While being part of one brand, the two companies were established as individual legal bodies and operate independently to a great extend.

As a casino game distributor, the online casino is placed at the end of the industry value chain (see Figure 3 ). Besides RNG games it offers a live casino, including mainly blackjack and roulette tables, and mobile games. Shared resources are utilized in the areas of HR, Finance, Business Intelligence (BI), IT, Product Development, and Customer Service. Conversely, these resources have their own Operations, Customer Relationship Management (CRM), and VIP Management departments. Their workforce is made up of nine employees, who are supervised by a head of Gaming. Since 2014 the company has grown its monthly turnover by around $71 \%$, its monthly Gross Gaming Revenue (GGR) by approx. 52\%, and introduced several new game suppliers.

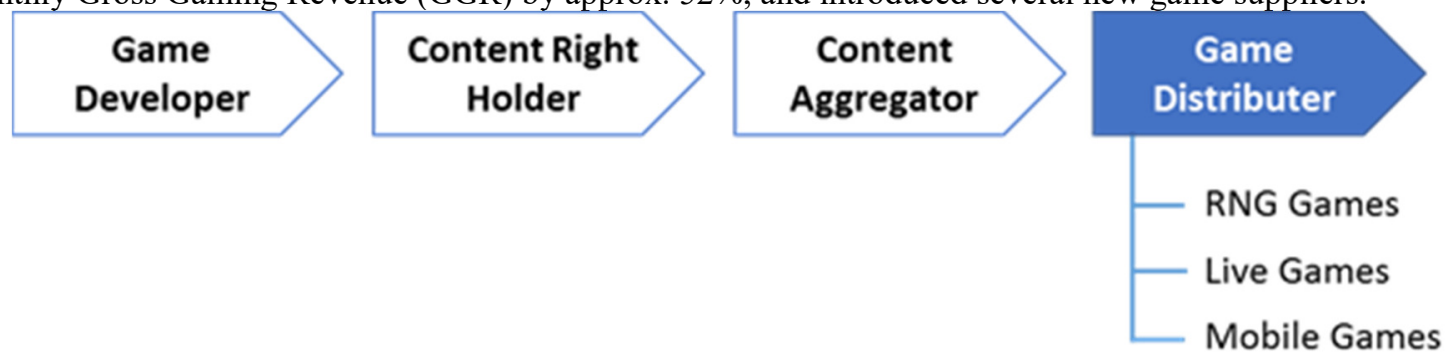

Figure 3. Industry value chain of online casinos \& Product portfolio (Basis: Meier \& Stormer, 2008)

For supervision and analysis purposes, a series of reports, monitoring the casino and game performance, is produced within the operations department. These main reports are split into daily, weekly and monthly reports (see Table 1 for the content of a weekly report). Additionally, specified ad hoc reports are produced in order to satisfy information requirements. 
Table 1. Weekly Casino Report as part of actual reporting system

\begin{tabular}{|c|c|}
\hline Report & Weekly Casino Report \\
\hline KPI & $\begin{array}{l}€ \text { GGR (target, per provider) } \\
€ \text { Turnover (per provider, per channel) } \\
\text { \# Daily unique players } \\
€ \text { Daily deposit } \\
\text { Best game ( } € \text { GGR per provider) }\end{array}$ \\
\hline Recipients & Operations, CRM, VIP Management, Head of Casino \\
\hline Function & Provide overview of last week and MTD performance \\
\hline Usage & Partially discussion point of current performance within weekly team meeting \\
\hline Poduction Time & 20 minutes \\
\hline
\end{tabular}

In mid-2016 a majority share of the brand was bought by a financial investor. Subsequently, a need for reviewing existing processes and further growth arose. Additionally, new technical features and resources enabled the introduction of new analysis areas, data driven decision making, and game management. Due to technical impediments the active management of game placement and portfolio was barely practiced before, while data analysis was often connected with complex data sourcing.

In other words, the new main shareholder expects to close existing gaps in industry standards and to achieve bottom-line targets. Consequently, short- to medium-term actions are to be favoured. Within the casino departments expectations include the possibility to combine the streamlining of efforts, their monitoring, and evaluation in a simplistic manner. Such efforts can be seen as contributors to the decrease of "firefighting initiatives" within the department.

In order to fulfil requirements and promote new practices, the online casino provider requires a common structure to define objectives, measure progress, and review achievements. However, established PM approaches appear unfit for the dynamic market environment and the size of the company. Limitations due to shared resources result in restricted product development time. Hence, the PMS should focus on developing objectives achievable by actions requiring no development time. These resource limitations further indicate concentration on effective objectives requiring less time and effort. Additionally, the company size demands a PMS that is low maintenance and simplified.

\subsection{Design of company-specific PMS}

As a future vision, the slogan 'from good to great' was created, combining the strengthening of current success and focus on future growth. For the online casino this results in two strategic focus areas. The first area is summarized by a 'mobile first' approach, which emphasizes the importance of the mobile product within the Internet Gaming industry. However, as the mobile value stream is subject to greater development procedures, this area will not be reflected within the PMS. The second area concerns the company's growth. A focus is placed on solid growth achieved by closing existing gaps to current competitors and leveraging costs. Despite the fact that these two areas exceed in the financial dimension, ultimate evaluation criteria are financial indicators.

Therefore, the central objective in the Financial Perspective is the increase of profit. This goal is to be accomplished in the two strategic focus areas of cost management and GGR increase. The objective is split according to the key processes backend and frontend/service. On the backend side, the main influencers of profit are costs. An improvement of the cost structure can contribute to an increase of bottom-line profit; main cost factors of the studied online casino are provider fees. On the frontend/service side, profit is determined by GGR, the actual earnings of the company. GGR is influenced by a variety of factors including turnover, active players, deposits and offer.

As a company operating in a highly competitive and regulated market, the External Environment is greatly influential. Customers are highly valuable stakeholders, whose motivations should be monitored and managed thoroughly. Within the Internet Gaming industry, direct comparisons of competitors are easily accessible for customers, who can view the expertise and standards regarding game portfolios and offers in this market. As compliance is a major contributor to the shaping of external views on a company, it is essential to operate within existing boundaries. The concerns of stakeholders as well as governments, industry associations, and regulatory 
authorities include tax payments, job creation, and community initiatives.

The achievement of the bottom-line results is greatly connected to the satisfaction of Customers. Only a satisfied customer will be loyal, recommend the casino to others, and increase his/ her gaming time. As stated earlier, the e-business environment of online casinos provides customers with the opportunity to compare competitors directly. Therefore, it is crucial to identify expectations and dissatisfying factors, e.g. response times, as well as improvement areas. Considering the fact that the online casino market is fiercely competitive, it is crucial to offer products and services that meet and - even better - excel the competitors' offers. In this context a marketing survey conducted by the casino company in 2016 found that $15 \%$ of customers hold active accounts with competitors.

Changes in all previously stated objectives are facilitated by appropriate Internal Processes. Collaboration is required within the frontend and service key processes. The casino's customer service, which is operated by shared resources, requires two-way communication. On the one hand, clear communication between the two individually operating departments is critical to quality of service; on the other hand, customer service as the point of direct customer contact represents a vital source of customer knowledge. Within the backend key process, the active management of game selection and placement is a process rarely established at the examined online casino. However, to improve game offering a structured process for game releases, website placement, and game promotion is necessary.

In order to develop, implement, and utilize improved internal processes Organizational Capabilities have to be identified and developed. In accordance with the internal processes and earlier defined strategic objectives, several knowledge and capability areas can be derived. Information about the casino's customers is an integral part of successful performance and unites all key processes from the capabilities perspective. On the frontend side, the CMS presents the creation tool for the casino website. It offers options for game placement, highlighting, and presentation. The key process backend requires game knowledge. It includes the awareness of existing games, new games, game popularity, game categories, game features, and their relevance.

Reviewing existing stakeholders confirmed that the five perspectives used within the proposed PMS are suitable and mirror the main interests of the online casino company (see Figure 4).

\section{Key Processes}

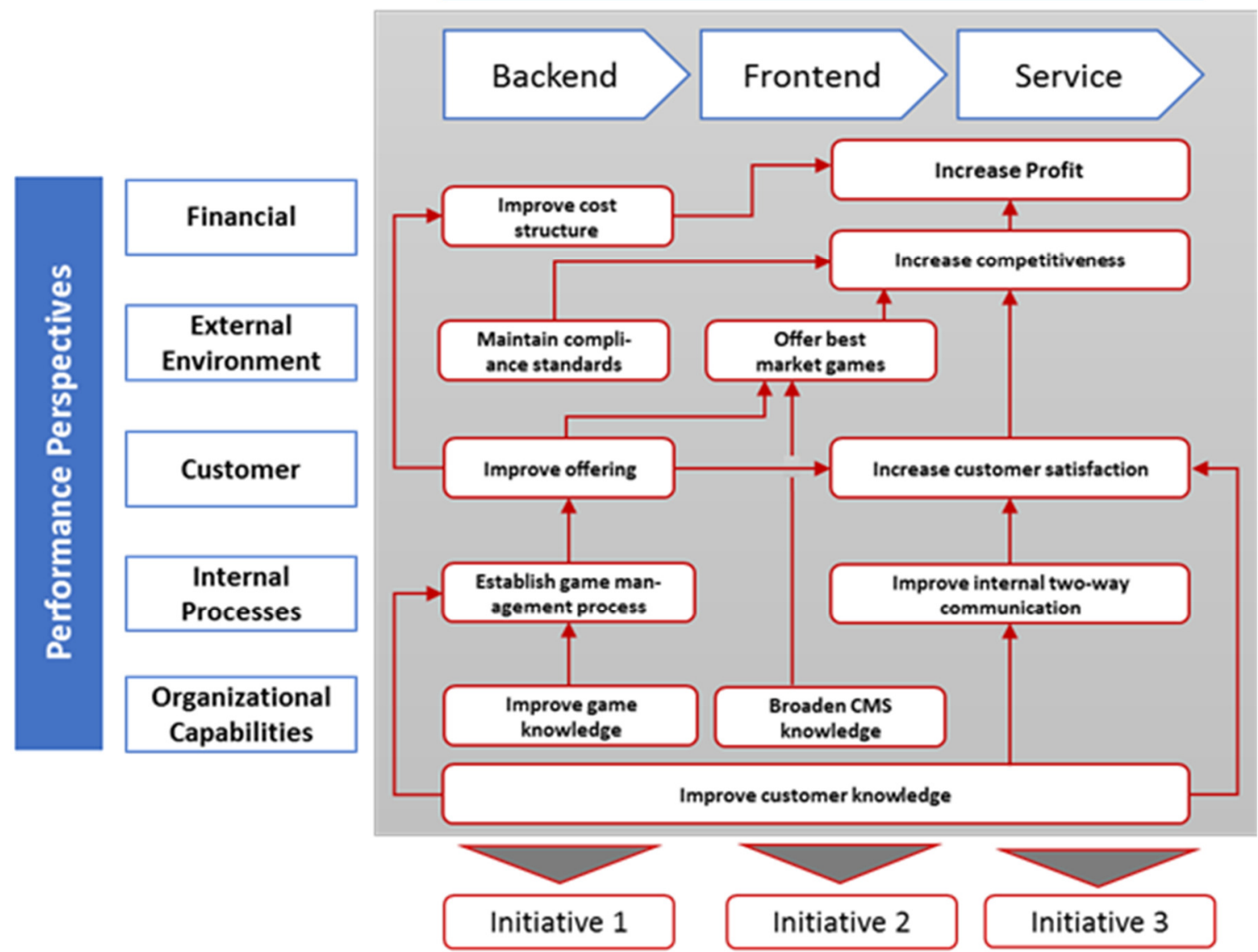

Figure 4. Individual PM framework for the examined online casino 


\subsection{Development of company-specific KPIs}

Based on the identified strategic objectives, we determined - in a second step - their relationships in greater detail and were able to link success factors to each of them. From these descriptions influencing factors and relevant measures (KPIs) could be derived (see Table 2). Besides relevance the selection of KPIs was influenced by accessibility. A focus was placed on indicators already used within reporting systems, instantly available by information systems or provided by external departments. In the process, previously disregarded measures were assigned significance. Furthermore, relevance of established KPIs was enhanced by the connection to context.

Table 2. Deduction of KPIs from strategic objectives and success factors

\begin{tabular}{|c|c|c|}
\hline Strategic Objective & Success Factor & Relevant Measure (KPI) \\
\hline Increase Profit & $\begin{array}{l}\text { GGR } \\
\text { Costs }\end{array}$ & $\begin{array}{l}\% \text { of GGR change } \\
\text { Margin } \\
\% \text { of cost change }\end{array}$ \\
\hline Improve cost structure & $\begin{array}{l}\text { Provider costs } \\
\text { Game costs } \\
\text { Marketing/CRM costs }\end{array}$ & $\begin{array}{l}\text { Provider fee/GGR } \\
\text { Game fee/ GGR } \\
\text { NGR/GGR }\end{array}$ \\
\hline Increase competitiveness & $\begin{array}{l}\text { Customer satisfaction } \\
\text { New customers } \\
\text { Market share } \\
\text { Customer lifetime }\end{array}$ & $\begin{array}{l}\% \text { of LTV change } \\
\% \text { of new depositors' change } \\
\text { Market Share } \\
\% \text { of active month/ player change }\end{array}$ \\
\hline Offer best market games & $\begin{array}{l}\text { New game availability } \\
\text { Game portfolio gaps }\end{array}$ & $\begin{array}{l}\text { Av. game implementation time } \\
\% \text { of network best game availability }\end{array}$ \\
\hline $\begin{array}{l}\text { Maintain compliance } \\
\text { standards }\end{array}$ & Compliance audits & $\%$ of audit compliance \\
\hline Improve offering & $\begin{array}{l}\text { Customer Spending } \\
\text { Customer use }\end{array}$ & $\begin{array}{l}\% \text { of LTV change } \\
\% \text { of Turnover/ Player change } \\
\text { Session Length } \\
\text { Session Depth }\end{array}$ \\
\hline $\begin{array}{l}\text { Increase customer } \\
\text { satisfaction }\end{array}$ & $\begin{array}{l}\text { Customer } \\
\text { Technical performance } \\
\text { Complaint management } \\
\text { Website offering }\end{array}$ & $\begin{array}{l}\% \text { of ARPU change } \\
\text { Churn rate } \\
\% \text { of Downtime } \\
\% \text { of complaint amount change } \\
\text { Av. case solving time } \\
\% \text { of NPV change } \\
\% \text { of CS rating change }\end{array}$ \\
\hline $\begin{array}{l}\text { Establish game management } \\
\text { process }\end{array}$ & $\begin{array}{l}\text { Game release plan } \\
\text { Game PM identification }\end{array}$ & $\begin{array}{l}\% \text { of plan accuracy } \\
\% \text { of task completion }\end{array}$ \\
\hline $\begin{array}{l}\text { Improve internal two-way } \\
\text { communication }\end{array}$ & $\begin{array}{l}\text { Knowledgeable contact person } \\
\text { Active communication }\end{array}$ & $\begin{array}{l}\text { Number of aware people } \\
\% \text { of preventive communication } \\
\% \text { of feedback communication }\end{array}$ \\
\hline Improve game knowledge & $\begin{array}{l}\text { Collected knowledge } \\
\text { Awareness }\end{array}$ & $\begin{array}{l}\text { Time invested in research } \\
\text { Growth of collected knowledge } \\
\% \text { of knowledgeable people }\end{array}$ \\
\hline Broaden CMS knowledge & $\begin{array}{l}\text { Collected knowledge } \\
\text { Awareness }\end{array}$ & $\begin{array}{l}\text { Time invested in research } \\
\text { Growth of collected knowledge } \\
\% \text { of knowledgeable people }\end{array}$ \\
\hline Improve customer knowledge & $\begin{array}{l}\text { Collected knowledge } \\
\text { Awareness }\end{array}$ & $\begin{array}{l}\text { Time invested in research } \\
\text { Growth of collected knowledge } \\
\% \text { of knowledgeable people }\end{array}$ \\
\hline
\end{tabular}


To explore the relevance of and connections to the identified measures in further detail, we set up a relationship matrix in order to highlight the direct and indirect relationships between measures and objectives. For example, the KPI ' $\%$ of customer satisfaction change' is considered to be as a strong indicator of the 'Increase customer satisfaction' objective. At the same time, the KPI acts as an indirect indicator of the objectives 'Improve competitiveness', 'Improve offering' and 'Improve customer knowledge'. This indicates the close connection between all objectives and their focus on the overall strategic goal. Individual record sheets support the establishment of a common understanding and perception of the selected KPIs.

In example, Table 3 provides a visual representation of the performance measure record sheet of KPI "Market Share". Furthermore, KPIs have been classified into lagging and leading indicators. In most cases the leading indicators can be found on the lower rungs of BSC' perspectives (see Tab. 2). As an overall result, we established a balanced system of financial and non-financial measures, reinforcing the growth orientation of the online casino.

Table 3. Example of a performance measure record sheet

\begin{tabular}{|l|l|}
\hline KPI & Market Share \\
\hline Description & Percentage of own GGR from total casino GGR volume in the relevant markets. \\
\hline Formula & \multicolumn{1}{|c|}{ Dedicated GGR in Germany 2017} \\
\hline Unit of measurement & $\%$ \\
\hline Purpose & Determine the relative competitiveness of the online casino offer in the relevant markets \\
\hline Relates to & $\bullet$ Increase competitiveness \\
\hline Source & $\bullet$ Casino monthly report \\
\hline Frequency & $\bullet$ H2 Gambling Capital report \\
\hline Owner & Quarterly \\
\hline
\end{tabular}

The defined KPIs accompany each strategic objective and monitor relevant changes. Nevertheless, these measures present limited informative value when viewed without context. Value is added when they are presented in a comparative format and measured against past performance. Further relevance within the PMS can be seen when compared with fixed targets. Setting targets should be aligned with bottom-line goals and company strategy. For example, the KPI "Market Share" is combined with the target "Increase of market share in Germany by 5\% in 2017".

\subsection{First results of PMS deployment}

For the studied online casino, the developed PMS offers the possibility of restructuring existing reporting systems, while streamlining strategy, objectives, and initiatives. The prior focus on financial indicators is balanced by performance perspectives highlighting external and internal progress.

Objectives relating to internal processes within the organizational capacities and internal process perspectives have not been previously measured, blocking the determination of successful completion and evaluation. Progress in internal effectiveness achieved was neither seen nor valued. Likewise, the examination of customer satisfaction did not include a technical performance and complaint management perspective. Consequently, critical success factors were disregarded in evaluation processes. The constructed system enables the immediate connection of customer dissatisfaction to failures in the provision of adequate services. Additionally, it stresses the necessity to implement internal communication structures that enable a higher service quality to improve overall performance. The developed PMS highlights these underlying factors and enables a more comprehensive assessment of performance. The inclusion of these factors in reporting systems raises awareness of the necessity of thinking in cause-and-effect terms. From a business perspective, it supports the future orientation of business decisions, and allows for multiple interpretation of performance. Objectives comprised within the organizational capabilities perspective have been recognized as fundamental because they are the building blocks of performance improvement. However, due to a change in ownership and additional personal developments, objectives and KPIs have not been fully confirmed yet.

\section{Conclusion}

The Internet Gaming industry, e.g. online casino business, is a fast growing and competitive sector. It requires constant striving for improvement. In the course of this paper, performance measurement was introduced as a strategic management tool, supporting such increases of effectiveness. 
Aligned with aforementioned objectives, a literature review was conducted and used as a guideline for the creation of a tailored online casino PMS for the examined casino company. Despite the underrepresentation of the online casino business in literature, the traditional BSC concept was presented and established as a feasible model which can be adjusted to suite specific industries. In regard to performance perspectives, non-financial measures and an environmental view were discovered to be valuable.

Furthermore, the paper translates these findings into a basic PMS for online casinos. The proposed system highlights relations between strategy' translation and key processes as well as stakeholders and performance perspectives. In conclusion, the paper provides an industry-related PMS, defining objectives and associated measures (KPI). Table 4 outlines the similarities and differences between the BSC and the adjusted PM approach for online casinos.

Table 4. BSC approach for online casinos - Summary of findings

\begin{tabular}{|l|l|l|}
\hline Criteria & \multicolumn{1}{|c|}{ BSC Standard Approach } & \multicolumn{1}{c|}{ BSC at Online Casinos } \\
\hline Depth & $\begin{array}{l}\text { 4 Levels of Analysis according to Kaplan/ } \\
\text { Norton }\end{array}$ & $\begin{array}{l}\text { 5 Levels of Analysis; additionally: "External } \\
\text { Environment" }\end{array}$ \\
\hline Perspectives & "Learning and Growth" on first level & $\begin{array}{l}\text { "Organizational Capabilities" on first level (due } \\
\text { to e-business/ artificial intelligence) }\end{array}$ \\
\hline Measures & $\begin{array}{l}\text { Balanced measures, incl. financial/ non- } \\
\text { financial measures and internal/ external }\end{array}$ & $\begin{array}{l}\text { Balanced measures, incl. financial/ non- } \\
\text { financial measures and internal/ external }\end{array}$ \\
\hline Focus & $\begin{array}{l}\text { Management of existing products and } \\
\text { business processes }\end{array}$ & $\begin{array}{l}\text { Management of new products and economic } \\
\text { growth }\end{array}$ \\
\hline Deployment & $\begin{array}{l}\text { Counter-current principle (combination of } \\
\text { top-down and bottom-up principle) }\end{array}$ & $\begin{array}{l}\text { Counter-current principle (combination of top- } \\
\text { down and bottom-up principle) }\end{array}$ \\
\hline
\end{tabular}

Accordingly, this paper contributes to knowledge within two fields of research. As a result of our research we could also identify several obstacles which can be overcome by steering future research in different directions as outlined below:

- First, it adapts performance measurement to special industries. However, as scientific literature concerning performance measurement systems (PMS) in online casinos is not available, a limited number of related literature was found and applied to the industry, e.g. e-business and services. Further research should elaborate on identifying comparable industries and fine-tuning existing theories and models for the online casino business. Additionally, country-specific regulations and laws should be considered in the conception of PMS criteria and KPI definitions.

- Second, management tools and methods that concern the operational aspects of the online casino business are outlined, and in doing so, this paper contributes to our understanding of this field. However, detailed work flows of online casinos and maintenance actions have not been discussed, further implying an ignorance of two important aspects of PMS. Therefore, future studies should focus on operational procedures within online casinos and provide aligned implementation strategies as well as execution guidelines. This inevitably leads to other research areas, e.g. change management $\&$ transition, that should be included in further research of this subject.

\section{List of Abbreviations}

ARPU - Average Revenue per user

BI - Business Intelligence

BSC - Balanced Scorecard

CMS - Content Management System

CRM - Customer Relationship Management

GGR - Gross Gaming Revenue

IT - Information Technology

KPI - Key Performance Indicator

LTD - Limited Company

LTV - Live Time Value MGA - Maltese Gaming Authority

NGR - Net Gaming Revenue

NPS - Net Promotor Score

PM - Performance Measurement 
PMS - Performance Measurement System

RNG - Random Number Generator

SME - Small and Medium sized Enterprise

\section{References}

1. Amir, a. M. (2014). Performance measurement system design in service operations: Does size matter? Management Research Review, (37), 728-749.

2. Balanced Scorecard Institute (2016). About the balanced scorecard. Balanced Scorecard Institute (12/ 2016). Retrieved from: http://balancedscorecard.org/Resources/About-the-Balanced-Scorecard

3. Barnes, D., \& Hinton, C. M. (2012). Reconceptualising e-business performance measurement using an innovation adoption framework. International Journal of Productivity and Performance Management, 61 (5), 502-517. https://doi.org/10.1108/17410401211232948

4. Bititci, U. S. (2015). Managing Business Performance: The Science and the Art. West Sussex, United Kingdom: Wiley \& Sons.

5. Bititci, U. S., Carrie, A. S., \& McDevitt, L. G. (1997). Integrated performance measurement systems: A development guide. International Journal of Operations \& Production Management, 17 (5), 522-535. https://doi.org/10.1108/01443579710167230

6. Bremser, W. G., \& Chung, Q. B. (2005). A framework for performance measurement in the e-business environment. Electronic Commerce Research and Applications, 4 (2005), 395-412. DOI:10.1016/j.elerap.2005.07.001

7. Business Dictionary (2016). Service business/ small and medium enterprise (SME). Business Dictionary (11/ 2016). Retrieved from: http://www.businessdictionary.com

8. Distelzweig, A. (2014). Performance Measurement in der Beschaffung. Wiesbaden, Germany: Springer Fachmedien.

9. European Gaming \& Betting Association (2016). Market Reality. Brussels, Belgium: European Gaming \& Betting Association.

10. Franceschini, F., Galetto, M., \& Maisano, D. (2007). Management by Measurement: Designing Key Indicator and Performance Measurement Systems. Heidelberg, Germany: Springer.

11. Gamblingsites.com (2016). History. Gamblingsites, 12/ 2016. Retrieved from: https://www.gamblingsites.com/history/

12. Garengo, P., Biazzo, S., \& Bititci, U. S. (2005). Performance measurement systems in SMEs: A review for a research agenda. International Journal of Management Reviews, 7 (1), 25-47. https://doi.org/10.1111/j.14682370.2005.00105.x

13. Gleich, R. (2011). Performance Measurement: Konzepte, Fallstudien und Grundschema für die Praxis. Munich, Germany: Vahlen.

14. Greiner, D. O. (2012). Balanced Scorecard: Erfahrungen, Erfolge und Probleme im praktischen Einsatz. In R. Gleich: Balanced Scorecard: Best-Practice-Lösungen für die strategische Unternehmensteuerung (pp. 65-84). Freiburg, Germany: Haufe.

15. Hudson, M., \& Bourne, M. (2001). Theory and practice in SME performance measurement systems. International Journal of Operations \& Production Management, 21 (8), 1096-1115.

16. Jaeaeskelaeinen, A., \& Laihonen, H. (2014). Distinctive features of service performance measurement. International Journal of Operations \& Production Management, 34 (12), 1466-1486. https://doi.org/10.1108/IJOPM-02-2013-0067

17. Kaisheng, Z., \& Xiaohui, L. (2011). Performance Measurement Systems for E-business. The 6th International Forum on Strategic Technology (1310-1313). Harbin, China: IEEE Press.

18. Manuela \& Larson (2013). Online casino. The game of their lives (12/ 2016). Retrieved from: http://www.thegameoftheirlives.com/onlinecasino.php

19. Meier, A., \& Stormer, H. (2008). eBusiness \& eCommerce (Vol. 2). Berlin, Germany: Springer.

20. Quotenmeter (2016). Rechtliche Situation von Online Casinos in Deutschland. Quotenmeter (12/ 2017). Retrieved from: http://www.quotenmeter.de/cms/print.php?id=86769

21. Reichmann, T. (2011). Controlling mit Kennzahlen: Die systemgestützte Controlling-Konzeption mit Analyseund Reportinginstrumenten. Munich, Germany: Vahlen.

22. Repetti, T. (2011). Recent Research Trends in the Gaming Industry: A Content Analysis of Research Literature on Casino Profits. UNLV Gaming Research \& Review Journal, 15(2), 91-108. https://digitalscholarship.unlv.edu/grrj/vol15/iss2/9

23. Richard, P. J., Devinney, T. M., Yip, G. S., \& Johnson, G. (2009). Measuring Organizational Performance: Towards Methodological Best Practice. Journal of Management, 35 (3), 718-745. https://doi.org/10.1177/0149206308330560

24.Schreyer, M. (2007). Entwicklung und Implementierung von Performance Measurement Systemen. Wiesbaden, 
Germany: Deutscher Universitätsverlag.

25. Straub, J. (2019). Das InterCasino im Test. CasinoOnline.de (06/ 2019). Retrieved from: https://www.casinoonline.de/tests/intercasino.php

26. Töpfer, A. (2000a). Balanced Score Card als ganzheitliches Managementkonzept. In A. Töpfer: Das Management der Werttreiber (pp. 69-106), Germany: FAZ.

27.Töpfer, A. (2000b). Messung und Messgrößen für die Gestaltungsfelder der Balanced Score Card. In A. Töpfer: Das Management der Werttreiber (pp. 124-144), Germany: FAZ.

28. Williams, R. J., \& Wood, R. T. (2007). Internet Gambling: A Comprehensive Review and Synthesis of the Literature. Guelph, Canada: Ontario Problem Gambling Research Centre. 